\title{
Presentation of congenital heart disease in infancy: implications for routine examination
}

\author{
Christopher Wren, Sam Richmond, Liam Donaldson
}

\begin{abstract}
Aim-To investigate the performance of routine neonatal and 6 week examinations for detecting congenital heart disease. Methods-A retrospective review of findings on clinical examination was conducted of a cohort of live born infants with congenital heart disease in one health region in 1987-94

Results-Of 1590 babies with congenital heart disease, $523(33 \%)$ presented before neonatal examination because of symptoms or non-cardiac abnormalities. 1061 underwent routine neonatal examination which was abnormal in 476 (45\%), but only 170 were referred directly for diagnosis. Of 876 discharged with no diagnosis, 306 presented or died undiagnosed before 6 weeks. At 6 weeks 252 of 569 babies underwent a second routine examination which was abnormal in $164(65 \%)$.

Conclusions-Routine neonatal examination fails to detect more than half of babies with heart disease; examination at 6 weeks misses one third. A normal examination does not exclude heart disease. Babies with murmurs at neonatal or 6 week examinations should be referred for early paediatric cardiological evaluation which will result either in a definitive diagnosis of congenital heart disease or in authoritative reassurance of normal cardiac anatomy and function.
\end{abstract}

(Arch Dis Child Fetal Neonatal Ed 1999;80:F49-F53)

Keywords: congenital heart disease; cardiac murmur; screening.

Unrecognised neonatal heart disease carries a serious risk of avoidable mortality, morbidity, and handicap. ${ }^{1}$ Examination before first discharge from hospital and of infants at 6 weeks of age for signs of congenital heart disease is

Table 1 Diagnostic categories and total infant mortality

\begin{tabular}{lcc}
\hline Diagnoses included & Number & Total infant mortality n (\%) \\
\hline Ventricular septal defect (VSD) & 590 & $35(6)$ \\
Pulmonary valve stenosis (PS) & 135 & $5(4)$ \\
Coarctation of aorta (COA) & 108 & $17(16)$ \\
Tetralogy of Fallot (TOF) & 99 & $10(10)$ \\
Simple transposition of great arteries (TGA) & 84 & $17(20)$ \\
Patent ductus arteriosus (PDA) & 81 & $2(2)$ \\
Complete atrioventricular septal defect (CAVSD) & 81 & $33(41)$ \\
Pulmonary atresia (PA) & 73 & $25(34)$ \\
Atrial septal defect, partial atrioventricular septal defect (ASD) & 71 & $9(13)$ \\
Aortic valve stenosis, subaortic stenosis, supravalvular stenosis (AS) & 67 & $14(21)$ \\
Hypoplastic left heart (HLH) & 45 & $45(100)$ \\
Total anomalous pulmonary venous connection (TAPVC) & 27 & $8(30)$ \\
Common arterial trunk (CAT) & 24 & $17(71)$ \\
Interruption of aortic arch (IAA) & 24 & $16(67)$ \\
Miscellaneous - other complex heart disease (MISC) & 81 & $17(21)$ \\
Total & 1590 & $270(17)$ \\
\end{tabular}

recommended in Health for All Children. ${ }^{2}$ We have already shown that most obstructive left heart malformations are not detected by these two examinations. Even when an abnormality (usually a murmur) is found, action is frequently not taken. ${ }^{3}$

We have now examined the performance of these two routine examinations in detecting all congenital heart disease within a large, geographically defined, population over a period of eight years.

\section{Methods}

We undertook a retrospective study of all cases nosed by the age of 12 months in babies live born in the northern health region of the UK between 1987 and 1994. This region covers a resident population of approximately $3.1 \mathrm{mil}-$ lion in the counties of Cumbria, Northumberland, Tyne and Wear, Cleveland and Durham. Babies from south Cumbria are referred to another region and were excluded from this study. Cases were identified from the Northern Regional Congenital Abnormality Survey which was established in 1985 and which has collected cumulative records of all congenital malformations affecting babies born to mothers resident in the study population. A detailed description of its methodology has been published before. ${ }^{4}$ A separate northern regional survey of perinatal, late neonatal, and infant mortality allowed babies with cardiovascular malformations who died before a cardiological diagnosis was made, to be identified. Data on total births were obtained from the Office of National Statistics.

Congenital heart disease was taken to be "a gross structural abnormality of the heart or intrathoracic great vessels that is actually or potentially of functional significance," as defined by Mitchell et al. ${ }^{6}$ Babies were included only if congenital heart disease was confirmed of structural congenital heart disease diag-
Paediatric Cardiolog

Newcastle upon Tyne C Wren

Neonatal Unit, Sunderland Royal

Hospital

S Richmond

Department of Epidemiology and Public Health University of Newcastle upon Tyne L Donaldson

Correspondence to: Dr Christopher Wren Department of Paediatric Cardiology, Freeman Hospital, Newcastle upon Tyne NE7 7DN.

Accepted 26 June 1998 


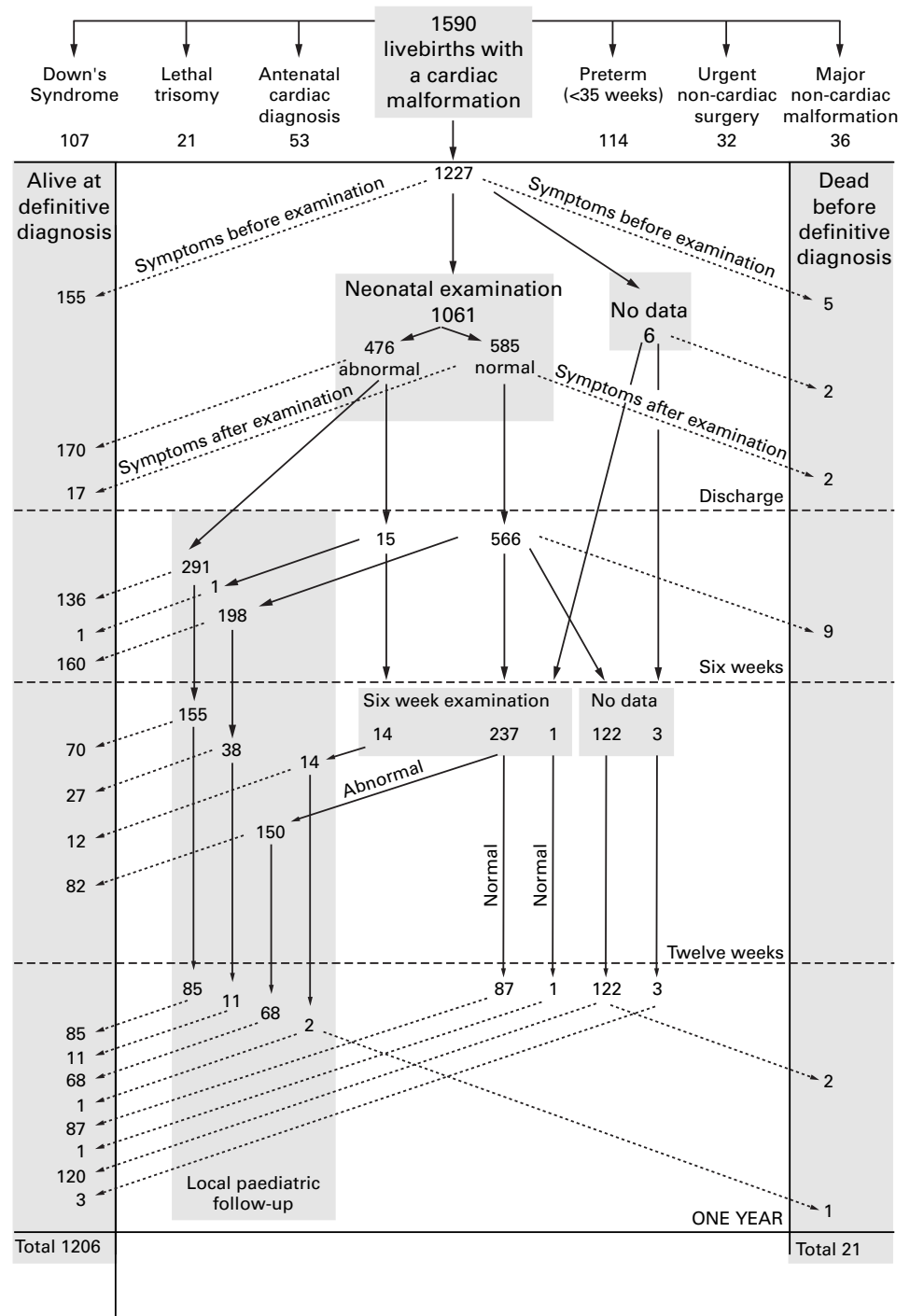

Figure 1 Flow chart showing how and when diagnosis of cardiovascular abnormality was achieved in all 1590 babies.

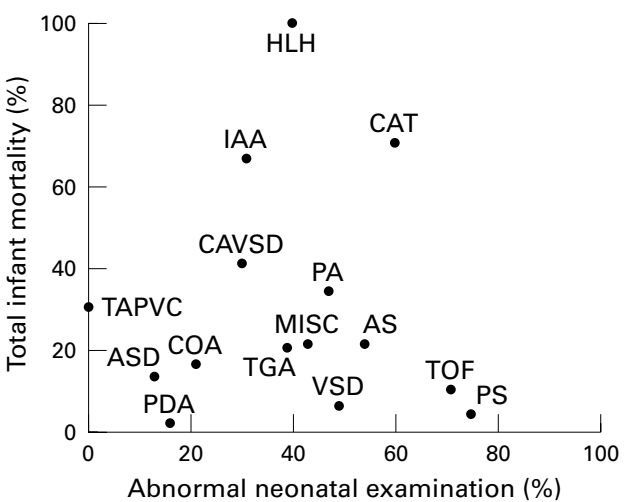

Figure 2 Relation between recognition of abnormality at routine neonatal examination and total infant mortality for each individual diagnostic group. Most deaths were due to cardiac malformation, with others accounted for by other abnormalities or a combination of factors.

The precise diagnosis was recorded. Babies with more than one cardiovascular abnormality were classified according to the malformation which precipitated presentation and which required earliest intervention. ${ }^{78}$ For example, a baby with double inlet left ventricle and coarctation of the aorta was classified by the latter abnormality even though the former was the more severe malformation and more significant in determining the long term outcome. Details of routine neonatal examination were sought by retrospective review of the notes from the hospital where the baby had been born, the paediatric cardiology case notes, and the perinatal mortality survey records. For the purposes of this study a routine neonatal examination was taken to be the examination of a newborn baby before first discharge from hospital after birth, when the baby was assumed to be normal at the start of the examination. Such examinations were performed almost exclusively by paediatric senior house officers. Detailed examination of a baby to whom medical attention was drawn because of illness or abnormality was not considered a routine neonatal examination. All babies with other major non-cardiac malformation, lethal trisomy (13 or 18), urgent surgical abnormalities (such as oesophageal atresia), or babies who were significantly preterm $(<1750 \mathrm{~g}$ or $<$ 35 weeks of gestation) were excluded from general analysis on the grounds that our definition precluded a routine examination. Babies with Down's syndrome and all babies with an antenatal diagnosis of congenital heart disease were excluded for the same reason.

We attempted to trace results of examination at 6 to 8 weeks in all babies unless congenital heart disease had already been diagnosed, or the baby was under general paediatric follow up for suspected heart disease, before that age. We refer to this as the 6 week examination for the purposes of this report.

\section{Results}

Between 1987-94 300102 babies were live born in the northern health region. Of 1590 who were found to have heart disease before the age of 12 months (table 1), we excluded from analysis $363(23 \%)$ for the reasons 
Table 2 Presentation of individual diagnoses, showing undiagnosed cases at each stage and performance of neonatal and 6 week examinations

\begin{tabular}{|c|c|c|c|c|c|c|c|c|c|c|c|c|c|c|c|c|}
\hline Diagnostic group & $V S D$ & $P S$ & $C O A$ & TOF & $T G A$ & $C A V S D$ & $P D A$ & $P A$ & $A S D$ & $A S$ & $H L H$ & $T A P V C$ & $C A T$ & $I A A$ & Miscellaneous & Totals \\
\hline Total cases (includes exclusions) & 590 & 135 & 108 & 99 & 84 & 81 & 81 & 74 & 71 & 67 & 45 & 27 & 24 & 24 & 80 & 1590 \\
\hline All exclusions & 101 & 23 & 13 & 27 & 8 & 62 & 26 & 10 & 33 & 9 & 10 & 5 & 6 & 5 & 25 & 363 \\
\hline Cases for analysis & 489 & 112 & 95 & 72 & 76 & 19 & 55 & 64 & 38 & 58 & 35 & 22 & 18 & 19 & 55 & 1227 \\
\hline $\begin{array}{l}\text { Not diagnosed before neonatal } \\
\text { examination }\end{array}$ & $\begin{array}{c}483 \\
99 \%\end{array}$ & $\begin{array}{c}108 \\
96 \%\end{array}$ & $\begin{array}{l}82 \\
86 \%\end{array}$ & $\begin{array}{l}63 \\
88 \%\end{array}$ & $\begin{array}{l}18 \\
24 \%\end{array}$ & $\begin{array}{c}19 \\
100 \%\end{array}$ & $\begin{array}{l}54 \\
98 \%\end{array}$ & $\begin{array}{l}32 \\
50 \%\end{array}$ & $\begin{array}{l}38 \\
100 \%\end{array}$ & $\begin{array}{l}57 \\
98 \%\end{array}$ & $\begin{array}{l}18 \\
51 \%\end{array}$ & $\begin{array}{l}20 \\
91 \%\end{array}$ & $\begin{array}{l}16 \\
89 \%\end{array}$ & $\begin{array}{l}13 \\
68 \%\end{array}$ & $\begin{array}{l}46 \\
84 \%\end{array}$ & $\begin{array}{l}1067 \\
87 \%\end{array}$ \\
\hline Received neonatal examination & 481 & 108 & 82 & 63 & 18 & 19 & 53 & 32 & 38 & 57 & 16 & 20 & 15 & 13 & 46 & 1061 \\
\hline Abnormal neonatal examination & 237 & 61 & 17 & 45 & 7 & 3 & 16 & 15 & 5 & 31 & 6 & 0 & 9 & 4 & 20 & 476 \\
\hline \multirow[t]{2}{*}{ Not diagnosed before discharge } & 407 & 90 & 72 & 41 & 13 & 15 & 47 & 20 & 36 & 49 & 12 & 19 & 11 & 9 & 35 & 876 \\
\hline & $83 \%$ & $80 \%$ & $76 \%$ & $57 \%$ & $17 \%$ & $79 \%$ & $85 \%$ & $31 \%$ & $95 \%$ & $84 \%$ & $34 \%$ & $86 \%$ & $61 \%$ & $47 \%$ & $64 \%$ & $71 \%$ \\
\hline \multirow[t]{2}{*}{ Not diagnosed before 6 weeks } & 289 & 66 & 26 & 20 & 3 & 8 & 44 & 7 & 31 & 39 & 0 & 11 & 5 & 0 & 21 & 570 \\
\hline & $59 \%$ & $59 \%$ & $27 \%$ & $28 \%$ & $4 \%$ & $42 \%$ & $80 \%$ & $11 \%$ & $82 \%$ & $67 \%$ & & $50 \%$ & $28 \%$ & & $38 \%$ & $46 \%$ \\
\hline Received 6 week examination & 136 & 24 & 18 & 7 & 1 & 6 & 19 & 2 & 14 & 13 & 0 & 2 & 1 & 0 & 9 & 252 \\
\hline Abnormal 6 week examination & 101 & 15 & 7 & 6 & 1 & 4 & 6 & 1 & 8 & 10 & 0 & 2 & 1 & 0 & 2 & 164 \\
\hline \multirow[t]{2}{*}{ Not diagnosed before 12 weeks } & 171 & 48 & 19 & 10 & 3 & 3 & 37 & 4 & 30 & 26 & 0 & 9 & 3 & 0 & 16 & 379 \\
\hline & $35 \%$ & $43 \%$ & $20 \%$ & $14 \%$ & $4 \%$ & $16 \%$ & $67 \%$ & $6 \%$ & $79 \%$ & $45 \%$ & & $41 \%$ & $17 \%$ & & $29 \%$ & $31 \%$ \\
\hline
\end{tabular}

explained above (fig 1). Of the remaining 1227 babies who were eligible for neonatal examination, 155 became symptomatic and were referred, and another five died undiagnosed, before routine neonatal examination. Thus 523 of 1590 (33\%) were diagnosed before routine examination, leaving 1067 in the study (fig 1).

Figure 1 shows the progress of each baby through the process of postnatal assessment. Of 1067 babies now known to have had congenital heart disease diagnosed in infancy and who underwent routine neonatal examination, $876(82 \%)$ had been discharged undiagnosed. General paediatric follow up had been arranged for 291 of the 306 recognised at the time as possibly having congenital heart disease. We found no evidence that the detection rate in the four units providing neonatal intensive care services to the region ( 220 of 475 cases, or $46 \%$ ) was any better than that of small units (256 of 586 cases, or $44 \%$ ).

By 6 weeks of age, 570 babies (54\%) remained undiagnosed, of whom 193 had been recognised at neonatal examination and were under general paediatric review. By 12 weeks of age, 379 babies (36\%) remained undiagnosed, 166 of whom had been recognised and were still under paediatric review.

We were unable to trace details of a neonatal examination in six of 1067 babies (0.6\%). Details of the 6 week examination were sought only in the 377 babies who were neither diagnosed nor under paediatric review by that age, but details of the examination could not be traced in 125 (33\%).

During the first year of life 21 babies died before diagnosis and a cardiovascular malformation was identified only at necropsy (fig 1). In 19 of 21 the malformation was sufficient to account for death.

Five died within 24 hours of birth-two with transposition of great arteries, one with hypoplastic left heart, one with coarctation of the aorta, and one baby who died from a non-cardiac cause, had a ventricular septal defect.

Four babies died between neonatal examination and discharge from hospital - two had a murmur before death (one with tetralogy of Fallot and one with hypoplastic left heart), and in two there were no data available (one with hypoplastic left heart and one with coarctation of the aorta).

Nine babies died between discharge and 6 weeks of age-three with interruption of the aortic arch, three with coarctation of the aorta, and one each with hypoplastic left heart, pulmonary stenosis, and pulmonary atresia. All died within three weeks of birth, either suddenly at home or after presenting to hospital in extremis following a short rapid deterioration.

Three babies died after 12 weeks of agetwo had severe aortic stenosis and one

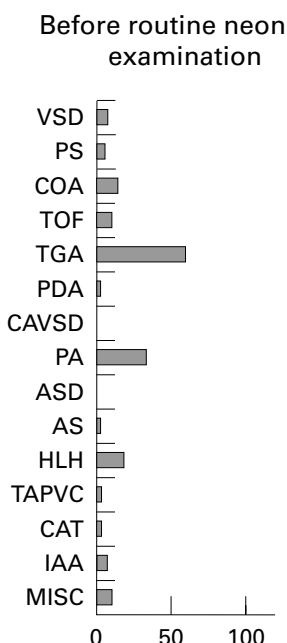

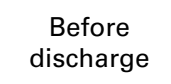

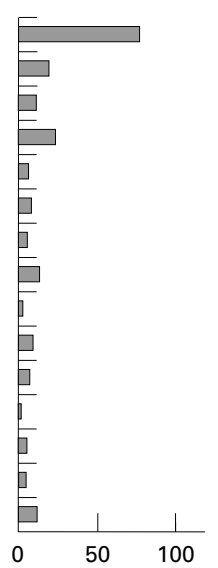

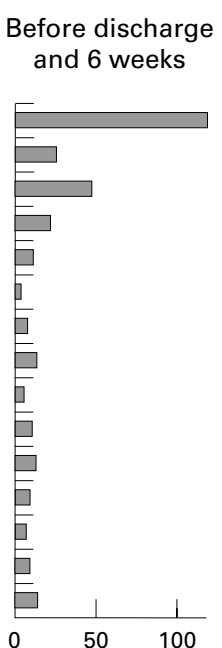

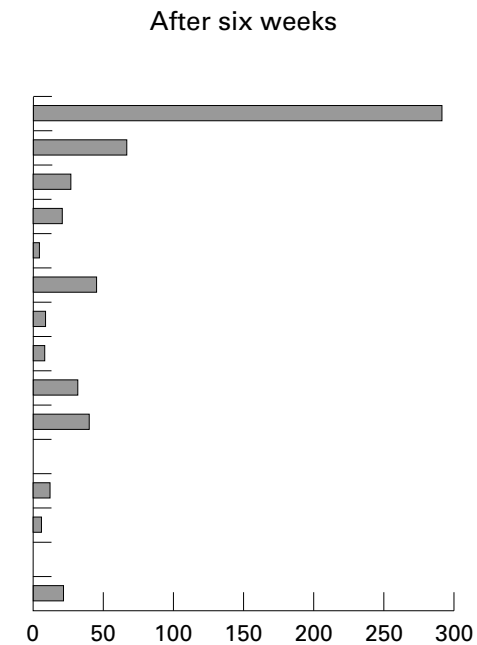

Figure 3 Timing of diagnosis and numbers of cases for each diagnostic group in 1277 babies eligible for routine examination. Displayed in this way, the spectrum of heart disease recognised at each stage is clearly shown. 
sustained a sudden infant death and was found to have an atrial septal defect at necropsy. Figure 1 shows that one of these babies (with aortic stenosis) had been recognised as abnormal at both the neonatal and 6 week examinations.

Our data do not suggest that severe heart disease is any easier to detect on routine examination than less serious heart disease (fig 2).

Table 2 shows the mode and timing of diagnosis by individual diagnostic group. The neonatal examination was abnormal in $0 \%$ to $73 \%$ of babies, with the lowest prevalence of murmurs in atrial septal defect and total anomalous pulmonary venous connection and the highest in aortic stenosis, pulmonary stenosis, truncus arteriosus and tetralogy of Fallot. The examination was abnormal in $49 \%$ of babies with a ventricular septal defect but in only $16 \%$ of those with a complete atrioventricular septal defect. Most abnormalities detected at neonatal examination were murmurs but the higher abnormality rates for transposition of the great arteries and pulmonary atresia reflect the detection of cyanosis. Figure 3 shows the numbers and the spectrum of abnormalities diagnosed at each stage.

Babies with Down's syndrome and heart disease were not part of the main study cohort (see methods) but are described here for completeness. Of 107 babies, nine were preterm, five had urgent surgical problems, and in five heart disease was recognised antenatally, leaving 88 with "isolated" Down's syndrome. As babies with Down's syndrome have a high prevalence of heart disease, ${ }^{9}$ the neonatal examination cannot be regarded as routine. Despite this, the cardiovascular abnormalities in this group were not readily detected. Only $41 \%$ had a clinical cardiovascular abnormality (almost always a murmur) on neonatal examination (table 3). Many babies were referred for early assessment and echocardiography simply because of Down's syndrome, yet $34 \%$ remained undiagnosed by 6 weeks of age and $24 \%$ by 12 weeks (table 3 ).

\section{Discussion}

Cardiovascular malformation is the most common group of congenital malformations. The prevalence at live birth diagnosed in infancy in this study was 5.3 cases per 1000 live births. This is consistent with previous large studies using similar methodology. ${ }^{10-12}$ Our register of live born congenital heart disease was set up in 1990 with prospective ascertainment of all cases since then but retrospective ascertain-

\section{Key points}

- More than half of babies with undiagnosed congenital heart disease which comes to light in infancy are missed by routine neonatal examination and more than one third by the 6 week examination

- Parents, community midwives, health visitors, general practitioners and paediatricians should recognise that a normal neonatal examination does not guarantee that the baby is normal and certainly does not exclude life threatening cardiovascular malformation

- Follow up of babies with murmurs without arranging for an early definitive (echocardiographic) diagnosis is of little value and can be risky

- Babies with murmurs at neonatal or 6 week examinations should be referred for early paediatric cardiological evaluation. This will result either in a definitive diagnosis of congenital heart disease or in authoritative reassurance of normal cardiac anatomy and function

- Babies with Down's syndrome have a high prevalence of congenital heart disease and all should be referred for early echocardiographic examination.

ment of cases in 1987-9. We are confident of complete ascertainment of all cases of complex or clinically significant heart disease throughout this study, but there was probably some under ascertainment of minor heart disease in 1987-1989. Recent prospective studies, with ready availability of early echocardiographic examination, have shown a higher of prevalence of live born heart disease, almost all of which is accounted for by the detection of more small ventricular septal defects. ${ }^{13-15}$

Early recognition of congenital heart disease is important because clinical presentation and deterioration may be sudden ${ }^{2}$ and some treatable defects may even cause death before diagnosis. ${ }^{316}$ Furthermore, in some cases early diagnosis can avoid irreversible pulmonary vascular disease. Clinical examination for signs of cardiovascular malformation is part of the recommended examination of neonates and 6 week old infants. ${ }^{2}$

We found that only $45 \%$ of babies with a cardiovascular malformation were considered to be abnormal on neonatal examination and in only $16 \%$ did the clinical findings lead to a

Table 3 Presentation of cardiovascular abnormalities in Down's syndrome, showing undiagnosed cases at each stage and performance of neonatal and 6 week examinations

\begin{tabular}{lccccccccc}
\hline Diagnostic group & CAVSD & VSD & ASD & TOF & PDA & COA & PS & Miscellaneous & Totals \\
\hline Total cases & 51 & 27 & 13 & 6 & 6 & 2 & 1 & 1 & 1 \\
Not diagnosed before birth & 47 & 26 & 13 & 6 & 6 & 2 & 1 & 1 & 107 \\
Remaining after other exclusions & 40 & 21 & 12 & 6 & 6 & 2 & 0 & 1 & 102 \\
Not diagnosed before neonatal examination & 36 & 20 & 12 & 4 & 6 & 2 & 0 & 1 & 88 \\
Received neonatal examination & 36 & 20 & 12 & 4 & 6 & 2 & 0 & 1 & 81 \\
Abnormal neonatal examination & 9 & 11 & 5 & 4 & 2 & 2 & 0 & 0 & 81 \\
Not diagnosed before discharge & 30 & 14 & 12 & 0 & 6 & 1 & 0 & 1 & 33 \\
Not diagnosed before 6 weeks & 18 & 12 & 5 & 0 & 1 & 0 & 0 & 0 & 64 \\
Received 6 week examination & 7 & 2 & 0 & 0 & 0 & 0 & 0 & 0 & 9 \\
Abnormal 6 week examination & 3 & 1 & 0 & 0 & 0 & 0 & 0 & 0 & 4 \\
Not diagnosed before 12 weeks & 13 & 8 & 4 & 0 & 1 & 0 & 0 & 0 & 26 \\
\hline
\end{tabular}


diagnosis before discharge from hospital. Seventeen babies passed as normal on routine neonatal examination later developed symptoms and were diagnosed before discharge home. One third of these had duct dependent lesions. With the trend to increasingly early discharge after delivery, such babies will be more likely to develop symptoms at home rather than when still on a postnatal ward.

Of the babies discharged home undiagnosed, $35 \%$ were diagnosed by 6 weeks of age and $57 \%$ by 3 months. If every baby who was found to have signs or symptoms of congenital heart disease had been examined echocardiographically within four weeks of the abnormality first being noted, 58\% could have been diagnosed by the time of the 6 week examination and $76 \%$ by three months. The nine babies who died undiagnosed between discharge and six weeks, would still not have been diagnosed in life as no signs of illness had been noted until immediately before death and all died before 4 weeks of age. However, one baby with aortic stenosis would have been diagnosed alive before six weeks instead of dying undiagnosed after 12 weeks.

In a previous study we showed that undiagnosed conditions most likely to lead to death soon after discharge from hospital were hypoplastic left heart, interruption of the aortic arch, and coarctation of the aorta. ${ }^{3}$ In the present study there was no relation between the likelihood of detection of abnormality and infant mortality for individual diagnoses (fig 2). The main implication of this finding is that a normal neonatal examination does not exclude serious or life threatening cardiovascular malformation. As about half of the babies noted to have murmurs in the first few days of life have structural heart disease, ${ }^{13}$ early referral of all such babies for cardiological assessment and echocardiography should be encouraged. We consider that continued local paediatric follow up in the absence of a confirmed diagnosis inappropriate. ${ }^{1}$

Many babies with life threatening cardiovascular malformation will have presented by 6 weeks of age (including all those with hypoplastic left heart or interruption of the aortic arch). However, in our study $27 \%$ of babies with coarctation were still undiagnosed by 6 weeks of age, and even by 3 months, $20 \%$ were still undiagnosed. Similarly, two thirds of babies with aortic valve stenosis were not diagnosed by six weeks and $45 \%$ by 12 weeks.

Data from the six week examination are not easily amenable to retrospective study. In many health districts there is no centralised record keeping. Despite an extensive search and good cooperation from local community paediatric departments, we could trace the results of the 6 week examination in only two thirds of the babies in whom we were interested. Even when an abnormality was suspected at the 6 week examination, this did not always lead to early diagnosis: only a third of those undiagnosed by six weeks were diagnosed by 12 weeks of age. Because about one quarter of babies noted to have a murmur at the six week examination have an underlying cardiovascular malformation, ${ }^{17}$ we recommend the need for early referral. ${ }^{1}$

Early diagnosis of heart disease in Down's syndrome is important firstly because both the parents and the paediatrician need to know the implications of the heart defect. Secondly some major malformations with pulmonary hypertension may show no signs and may progress to irreversible pulmonary vascular disease before the heart defect has been recognised. ${ }^{2}$ Despite this we found that in a third of babies with Down's syndrome and heart disease no diagnosis had been made by 6 weeks and a quarter remained undiagnosed as late as 3 months of age.

The study was funded by the former Northern and Yorkshire Regional Health Authority. The paediatric cardiology database is funded by the Children's Heart Unit Fund. We are indebted to Susan Fritz, who collected the data and to all our colleagues who provide sustained support for the regional perinatal, late neonatal, and infant mortality survey to allow collection of accurate mortality data.

1 Silove ED. Assessment and management of congenital heart in the newborn by the district paediatrician. Arch Dis Child in the newborn

2 Hall DMB, ed. Health for all children. Report of the third joint working party on child health surveillance. Oxford: Oxford University Press, 1996.

3 Abu-Harb M, Hey E, Wren C. Death in infancy from unrecognised congenital heart disease. Arch Dis Child 1994;71:3-7.

4 Northern Regional Survey Screening Group. Fetal abnormality, an audit of its recognition and management. Arch Dis Child 1992;67:F770-4.

5 Northern Regional Health Authority Coordinating Group. Perinatal mortality: a continuing collaborative regional Perinatal mortality: a continuing

6 Mroup. BMf Kell SC, Korones SB, Berendes HW. Congenital heart disease in 56,109 births. Circulation 1971:43:323-32.

7 Moller JH, Moodie DS, Norton JB, Nouri S. Symptomatic heart disease in infants: Comparison of three studies performed during 1969-1987. Paediatr Cardiol 1995;16:21622.

8 Jackson M, Walsh KP, Peart I, Arnold R. Epidemiology of congenital heart disease in Merseyside - 1979 to 1988. Cardiol Young 1996;6:272-80.

9 Wyllie JP, Madar RJ, Wright M, Burn J, Wren C. Strategies for antenatal detection of Down's syndrome. Arch Dis Child 1997;76:F26-30

10 Ferencz C, Rubin JD, McCarter RJ, et al. Congenital heart disease: prevalence at live birth. $A m$ f Epidemiol 1985;121:31-6.

11 Grabitz RG, Joffres MR, Collins-Nakai RL. Congenital heart disease: incidence in the first year of life. Am $\mathcal{F}$ Epidemiol 1988;128:381-8.

12 Kidd SA, Lancaster PAL, McCredie RM. The incidence of congenital heart defects in the first year of life. $\mathcal{F}$ Paediatr Child Health 1993;29:344-9.

13 Ainsworth SB, Wyllie JP, Wren C. Prevalence and clinical significance of cardiac murmurs in neonates. Arch Dis Child 1999;80:F43-5.

14 Hiraishi S, Agata Y, Nowatari M, et al. Incidence and natural course of trabecular ventricular septal defect: Twodimensional echocardiography and color Doppler flow imaging study. F Pediatr 1992;120;409-15.

15 Roguin N, Du ZD, Barak M, Nasser N, Hershkowitz S. High prevalence of muscular ventricular septal defect in High prevalence of muscular ventricular sep
neonates. Am Coll Cardiol 1995;26;1545-8.

16 Abu-Harb M, Wyllie J, Hey E, Richmond S, Wren C. Presentation of obstructive left heart malformation in infancy. Arch Dis Child 1994;76:F179-83.

17 Gregory J, Emslie A, Wyllie JP, Wren C. Examination for cardiac malformations at six weeks of age. Arch Dis Child 1999;80:F46-8 